\title{
65+ YAŞLI BİREYLERİN ANTROPOMETRİK REFERANS DEĞERLERİ VE ERGONOMİ İLİŞKİİ
}

\author{
Gülüşan ÖZGÜN BAŞıBÜYÜK ${ }^{*}$, Zümre ÖZDEMİR GÜLER², Barıș KILIÇ³, Faruk AY4
}

${ }^{1}$ Akdeniz Üniversitesi, Sağlık Bilimleri Fakültesi, Gerontoloji Bölümü ORCID No: http://orcid.org/0000-0002-2801-6157

2 Karamanoğlu Mehmetbey Üniversitesi, İktisadi ve İdari Bilimler Fakültesi, Ekonometri Bölümü ORCID No: http://orcid.org/0000-0003-2730-4584

${ }^{3}$ Akdeniz Üniversitesi, Sağlık Bilimleri Fakültesi, Gerontoloji Bölümü ORCID No: http://orcid.org/0000-0002-0969-0736

${ }^{4}$ Sivas Cumhuriyet Üniversitesi, Edebiyat Fakültesi, Antropoloji Bölümü ORCID No: http://orcid.org/0000-0002-4201-4422

\begin{tabular}{l}
\hline Anahtar Keli \\
\hline Yaşlı \\
Ergonomi \\
Antropometri \\
Yaşlanma \\
Tasarım
\end{tabular}
\section{Öz}

Yaşamın her evresinde olduğu gibi yaşlılıkta da yaşam kalitesinin yükseltilmesi, doğru bir tasarım planlaması ve birtakım prensiplerin uygulanması ile mümkündür. Bunun için ergonomistler antropometriden yararlanırlar. Antropometrik veriler ışığında ergonomik yaklaşımlar yaşlılar için; iç-dış mekân düzenlemeleri ve günlük yaşamı destekleyecek tasarımlar için gereklidir. Çünkü yaşlı popülasyonunun yetenekleri ve kısıtlılıkları bilinmedikçe veya dikkate alınmadıkça ergonomik tasarımlar bașarılı olamazlar. TÜBİTAK 115M548 No'lu “Anadolu Yaşlılarının Antropometrik Boyutları" adlı 1001 projesi kapsamında, Türkiye'nin yedi bölgesindeki 26 ilden toplam 2721 bireyin antropometrik verileri alınmıştır. Alınan ölçümler literatürde yaygın olarak kullanılan ortalama (Ort.), standart sapma (SS), standart hata ortalaması (SHO), değişim katsayısı (DK) ile 5., 50. ve 95. yüzdelikleri bakımından değerlendirilmiștir. Veriler SPSS 26. programıyla analiz edilmiștir. Araștırmadan edinilen bilgilere göre; DK (\%) sonuçları değerlendirildiğinde en yüksek değerler kadınlarda oturma yeri dirsek yüksekliği 23,40, erkeklerde oturma yeri dirsek yüksekliği 21,07'dir. En küçük DK değerleri ise kadınlarda kafa uzunluğu 4,11, erkeklerde kafa uzunluğu 4,13'tür. Bununla birlikte, SHO ile ilgili olarak, en yüksek SHO değerleri erkekler 2,24 ve kadınlar 2,10 için ayakta göz yüksekliği değerleridir. Genel ağırlı ortalamasının erkekler 75,49 $\mathrm{kg}$ ve kadınlar 70,51 kg olduğu görülmektedir. Genel boy ortalaması ise erkekler 163,86 cm ve kadınlar 148,85 cm'dir. DK değerlerinin büyük olması veride değişkenliğin yüksek olduğunun göstergesidir. Dolayısıla DK ne kadar büyükse tasarım kararları da o kadar zor olacaktır. Ayrıca büyük SHO değerine sahip boyutlar ile örneklemden popülasyona yönelik genellemeler yapmak zor olabileceğinden değerlendirmeler dikkatlice yapılmalıdır. Bu nedenle; yaşlı bireylerin refah düzeylerinin arttırılması amacıyla yapılan tasarımlarda araștırma verileri göz önünde bulundurulmalı ve dikkatlice kullanılmalıdır.

\section{THE RELATIONSHIP OF 65+ OLDER PEOPLE WITH ANTHROPOMETRIC REFERENCE VALUES AND ERGONOMICS}

\begin{tabular}{l}
\hline Keywords \\
\hline Older Adults \\
Ergonomics \\
Anthropometry \\
Aging \\
Design
\end{tabular}

\section{Abstract}

As in every phase of life, increasing the quality of life in old age is possible with a correct design planning and application of some principles. For this, ergonomists make use of anthropometry. Ergonomic approaches with the help of anthropometric data for the older adults; It is necessary for indoor-outdoor arrangements and designs that will support daily life. Because ergonomic designs cannot be successful unless the capabilities and limitations of the older adults are known or ignored. Anthropometric data of a total of 2721 individuals from 26 provinces in seven regions of Turkey were obtained within the scope of TÜBİTAK's 1001 project "Anthropometric Dimensions of the Older Adults in Anatolia" No. 115M548. The measurements taken were evaluated in terms of mean (Avg.), standard deviation (SD), standard error mean (SHO), coefficient of variation (DK) and 5th, 50th and 95th percentiles, which are commonly used in the literature. Data were analyzed with SPSS 26. program. According to the information obtained from the research; When the DK (\%) results were evaluated, the highest values were found to be 23.40 for women and 21.07 for men. The smallest $D K$ values are head length 4.11 for females and 4.13 for males. However, with regard to $\mathrm{SHO}$, the highest SHO values are standing eye height values for men 2.24 and women 2.10. It is seen that the overall weight average is $75.49 \mathrm{~kg}$ for men and $70.51 \mathrm{~kg}$ for women. The general average height is $163.86 \mathrm{~cm}$ for men and $148.85 \mathrm{~cm}$ for women. High DK values indicate high variability in the data. Therefore, the larger the $D K$, the more difficult the design decisions will be. In addition, evaluations should be made carefully, as it may be difficult to generalize from sample to population with dimensions with large SHO values. Because; Research data should be considered and used carefully in designs made to increase the welfare level of older people.

\begin{tabular}{llll}
\hline Araştırma Makalesi & & Research Article & \\
Başvuru Tarihi & $: 27.10 .2021$ & Submission Date & $: 27.10 .2021$ \\
Kabul Tarihi & $: 03.12 .2021$ & Accepted Date & $: 03.12 .2021$ \\
\hline
\end{tabular}

\footnotetext{
*Sorumlu yazar e-posta: gozgun@akdeniz.edu.tr
} 


\section{Giriş}

Günümüzde tıp biliminin ve tıbbi teknolojinin gelişmesiyle hastalıkların kontrol altına alınması, tanı ve tedavisinin erken yapılabilmesi, yaşam koşullarının iyileştirilmesi; ortalama yaşam süresinin uzamasına ve dünyada yaşlı nüfusun artmasına neden olmuştur. Ülkemizde 65 yaş ve üzeri nüfus oranı; 2015 yılında 6 milyon 495 bin 239 kiși ile \%8,2 iken son 5 yılda \%22,5'lik bir artış ile 2020 yllında 7 milyon 953 bin 555 kişi ile \%9,5’e yükselmiştir (TÜÍK, 2021). Bu oranın git gide artacağı öngörülerek yaşlı nüfusun ülkemizin politikalarındaki dağılımında önemli bir paya sahip olacağı düşünülmektedir. Bu sebep ile ekonomik ve sosyal sistemin, artan yaşlı nüfusun ihtiyaçlarına çözüm getirebilecek bir yapıya bürünmesi gerekmektedir (Tufan, 2015).

Yaşlılık; daha fazla çevresel dinamizmi tanımayı, daha fazla yaşam deneyimi kazanmayı ve daha geniş sosyal ilişkilere sahip olma gücünü ifade etmektedir.

Günümüzde çekirdek aile yapısı yaşlıların aile içindeki yerinin azalmasına, bu durum da yaşlılara ayrı ev tutulmasina, huzurevlerine veya bakımevlerine yerleştirilmelerine neden olmaktadır. Bununla birlikte yaşlı nüfusun da artmasıyla yaşlılar çevresel risklerle daha iç içe hale gelmektedirler (Özgün Başıbüyük vd., 2018).

Yaşlılık, yaşam süreçlerinden sadece biridir ancak yaşam seyri boyunca içsel ve çevresel birçok sebep nedeniyle yaşlılıkta birtakım kısıtlılıklar daha yoğun görülmekte veya daha belirgin hale gelmektedir. Yaşın artmasıyla iskelet, kas ve sinir sistemindeki değişiklikler ile insanın fiziksel, psikomotor, duygusal ve algisal kapasitesinde de azalmalar meydana gelmektedir. $\mathrm{Bu}$ durum da temel ve enstrümental günlük yaşam aktivitelerinde engellere sebep olmaktadır. Bunların yanı sıra iç veya dış mekanlardaki yaşlıların antropometrik verilerini göz ardı eden tasarımlar yaşlı bireylerde biyopsikososyal bozuklukların gelişme riskini arttırabilir (Eyvazi ve Mokhtarinia, 2017)

Ergonomi; insanın yeteneklerine, kısıtlılıklarına ve diğer özelliklerine dayanan bir bilim dalıdır. İnsan ve çevre arasındaki uyumu arttırabilir, kısıtlılıkları en aza indirebilir ve engelliliğe giden süreci etkileyebilir. Yaşlı bireylerin ihtiyaçları, istekleri, sağlık durumları, yaşadıkları sorunlar, çevresel faktörler, özellikle fizyolojik ve fiziksel yetileri göz ardı edilemez. Ergonomistler yașlıları da düşünerek yaşam alanlarının ve ürünlerin tasarımını değiştirmeli veya yeni tasarımlar oluşturmalıdırlar. $\mathrm{Bu}$ hedeflere ulaşmak için, ergonomistler çeşitli teknikler kullanırlar ve antropometri de bunlardan biridir (Eyvazi ve Mokhtarinia, 2017).

Antropometri, Yunanca anthropo (insan) ve metrikos (ölçme) sözcüklerinden türetilmiştir ve özellikle fiziki antropolojide kullanılan, tüm yaş gruplarında insan vücudunun fiziksel boyutlarını sayısal olarak ölçme esasları ile boyutlandıran ya da metrik olarak tanımlayan, değerlendiren, sistematik tekniklere dayalı bir yöntemdir. Antropometrik ölçümler Anthropometric Standardization Referance Manual (ASRM) ve International Biological Programme (IBP)'nin öngördüğü teknikler doğrultusunda alınarak; bireyin boy, uzunluk, çevre, deri kalınlığı, vücut tipi, vücut bileşiminin orantıları gibi statik verilerin yanı sıra; hareket sınırları gibi dinamik veriler de belirli noktalar esas alınarak ortaya konur, bireylerin birbirleriyle karşılaştırılmaları sağlanır ve standart değerler oluşturulur (Lohman vd., 1988; Weiner ve Lourie, 1981). Oluşturulan standart değerler başta ergonomi olmak üzere birçok alanda bireylerin araçgereç, donanım ve mekanların boyutları ile uyumunun tespiti için kullanımında önem arz etmektedir. Toplumların veya bireylerin sağlık, beslenme, fiziksel durumlarının izlenmesinde kullanılmasıyla doğrudan tıp alanında da kullanımı söz konusudur. Antropometri ile bireysel ve toplumsal özellikler ucuz, pratik ve tatmin edici bir şekilde ortaya konularak; ileriki yıllarda oluşabilecek sağlık problemleri, fonksiyonel bozukluklar ve mortalite ilișkisi belirlenebilmektedir. Elde edilen bilgi ile olası problemleri önlemeye yönelik geliștirilebilecek çalışmalara da referans oluşturularak; neredeyse tüm popülasyona uygun evrensel tasarıma yönelik yeni bir tasarım yaklaşımına katkı sağlamak hedeflenmelidir. Antropometrik ölçümler, fiziksel ve bilişsel yetenekler ve sınırlılıklar ile ilgili doğru ve güvenilir veriler toplanıp analiz edilmedikçe ergonomistler bunu gerçekleştirmekte zorlanacaktırlar (Lohman vd., 1988; Weiner ve Lourine, 1981).

Antropometrik veriler ışı̆̆ında ergonomik yaklaşımlar yaşlılar için; oturma odaları, yatak odaları, mutfak, banyo, tuvalet, mobilya, iş istasyonları gibi iç mekân; sokak, kaldırım, merdiven, asansör, alışveriş merkezleri, parklar ve hizmet alanları gibi dış mekân düzenlemeleri ve günlük yaşamı destekleyecek, kolaylaştıracak, güvenli ürünlerin tasarımı için gereklidir (Kaewdok, 2020; Özalp, 2020; Rahmawati vd., 2020).

Yaşlının antropometrik özelliklerini dikkate alarak tasarlanan veya düzenlenen ergonomik mekân ve aletler yaşlıların yalnızca bağımsız yașamasını kolaylaştırmayı sağlamaz, ayrıca yaşam kalitelerini arttırarak çoğu kazayı ve kazalar sonucu oluşabilecek hastalık, sakatlık, engellilik ve bakıma muhtaçlık durumlarını da engelleyebilir. Ev kazaları yaşlı bireylerin karşılaştıkları kazaların \%82'lik kısmını oluşturmaktadır. Yaşlıların karşılaștığı kazaların çoğu kolayca gözden kaçabilen ancak kolaylıkla da ortadan kaldırılabilecek bireysel ve 
çevresel etmenlerden kaynaklanmaktadır. (Jarosz, 1999; Aydıner Boylu, 2013; Dianat vd., 2018; Akkaya Kozak, 2021).

\section{Yöntem}

TÜBİTAK 115M548 no'lu “Anadolu Yaşlılarının Antropometrik Boyutları" isimli 1001 Projemiz kapsamında; TÜİK Adrese Dayalı Nüfus Kayıt Sistemi verileri doğrultusunda tabakalı örnekleme yöntemi kullanılarak Türkiye'nin 7 bölgesinin her biri tabaka olarak tanımlanmış olup, bu tabakalardan 26 il örnekleme birimi olarak belirlenmiştir. Çalışmamız 7 bölgede 26 ilden; 65-74 yaş, 75-84 yaş, 85+ yaş olarak üç grupta toplam 2721 bireyi kapsayacak şekilde, 2016-2017 yılları arasında yapılan alan çalışması ile tamamlanmıştır. Alan araştırmasında 2721 bireyin her birisinden alınan 55 antropometrik ölçüden; 49 tanesi bu çalışmaya dahil edilmiştir (Tablo 1). Etik onayı, Cumhuriyet Üniversitesi Etik Kurulu tarafından 2014-03/15 numarası ile verilmiştir. Çalışmaya katılmadan önce her katılımcıya yazılı ve sözlü bilgilendirilmiş onam sunulmuştur.

\section{1. İstatistiksel Analiz}

Çalışmaya dahil olan katılımcıların antropometrik ölçümleri literatürde yaygın olarak kullanılan ortalama (Ort.), standart sapma (SS), standart hata ortalaması (SHO), değişim katsayısı (DK) ile 5., 50. ve 95. yüzdelikleri bakımından değerlendirilmiştir. Daha sonra, erkek ve kadın katılımcılar arasındaki antropometrik ölçüm farklılıkları bağımsız örnekler için t-testi ile değerlendirilmiştir. Veriler Sosyal Bilimler için İstatistik Paketi (SPSS)'nin 26. versiyonu kullanılarak analiz edilmiştir. İstatistiksel önemi belirtmek için anlamlılık düzeyi $\% 5$ olarak alınmıştır.

\section{Bulgular}

Çalışmada öncelikle katılımcıların farklı yaş grupları ve cinsiyetlerine göre sırasıyla yaş ortalamaları, boy ortalamaları ve ağırlık ortalamaları Şekil 1, Şekil 2 ve Şekil 3'te sunulmuştur.

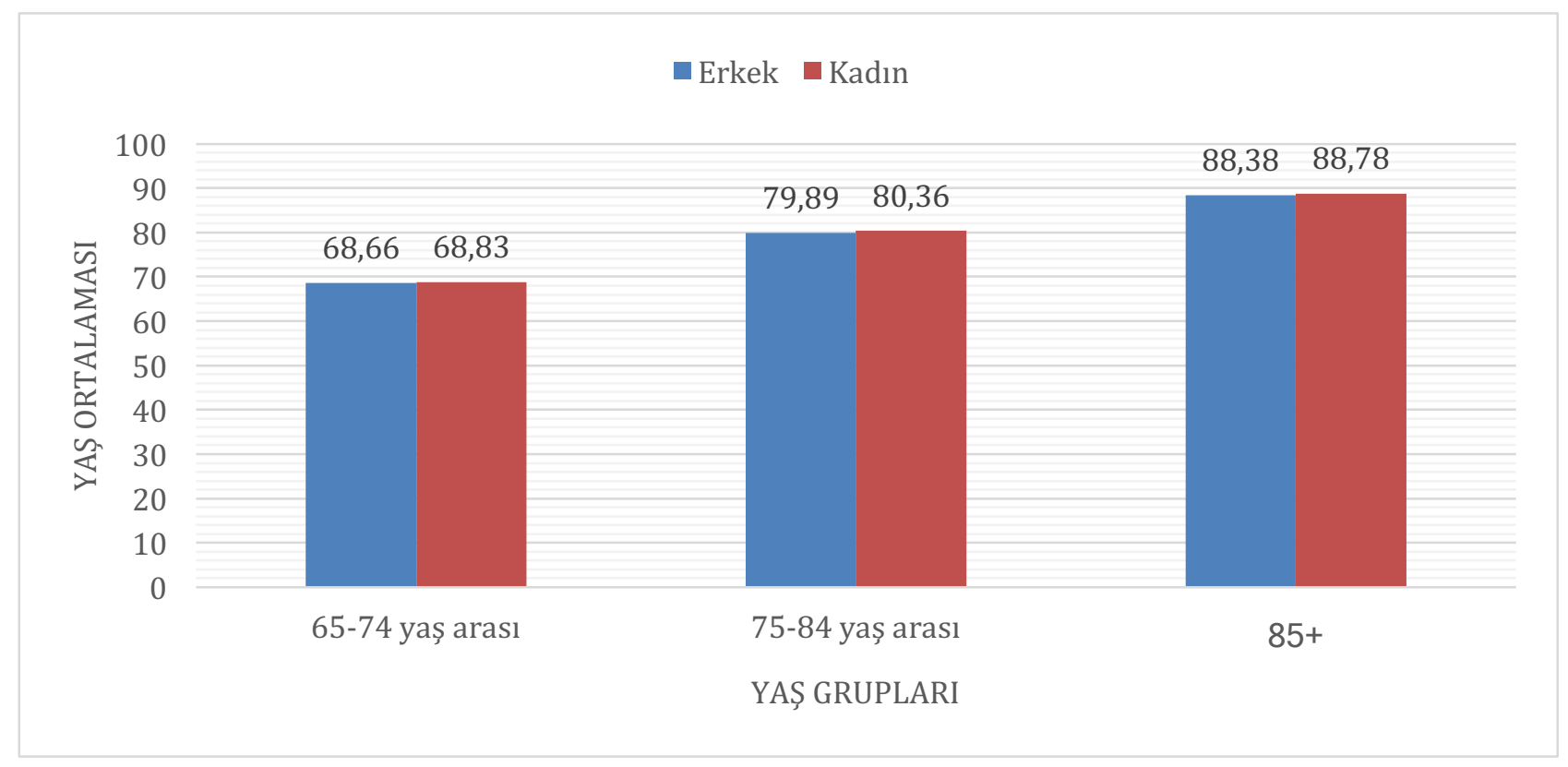

Şekil 1. Farklı Yaş Grupları Ve Cinsiyetlere Göre Katılımcıların Yaş Ortalamaları

Şekil 1'e bakıldığında hem erkek hem de kadın katılımcıların yaş ortalamalarının birbirine oldukça yakın oldukları görülmektedir. 


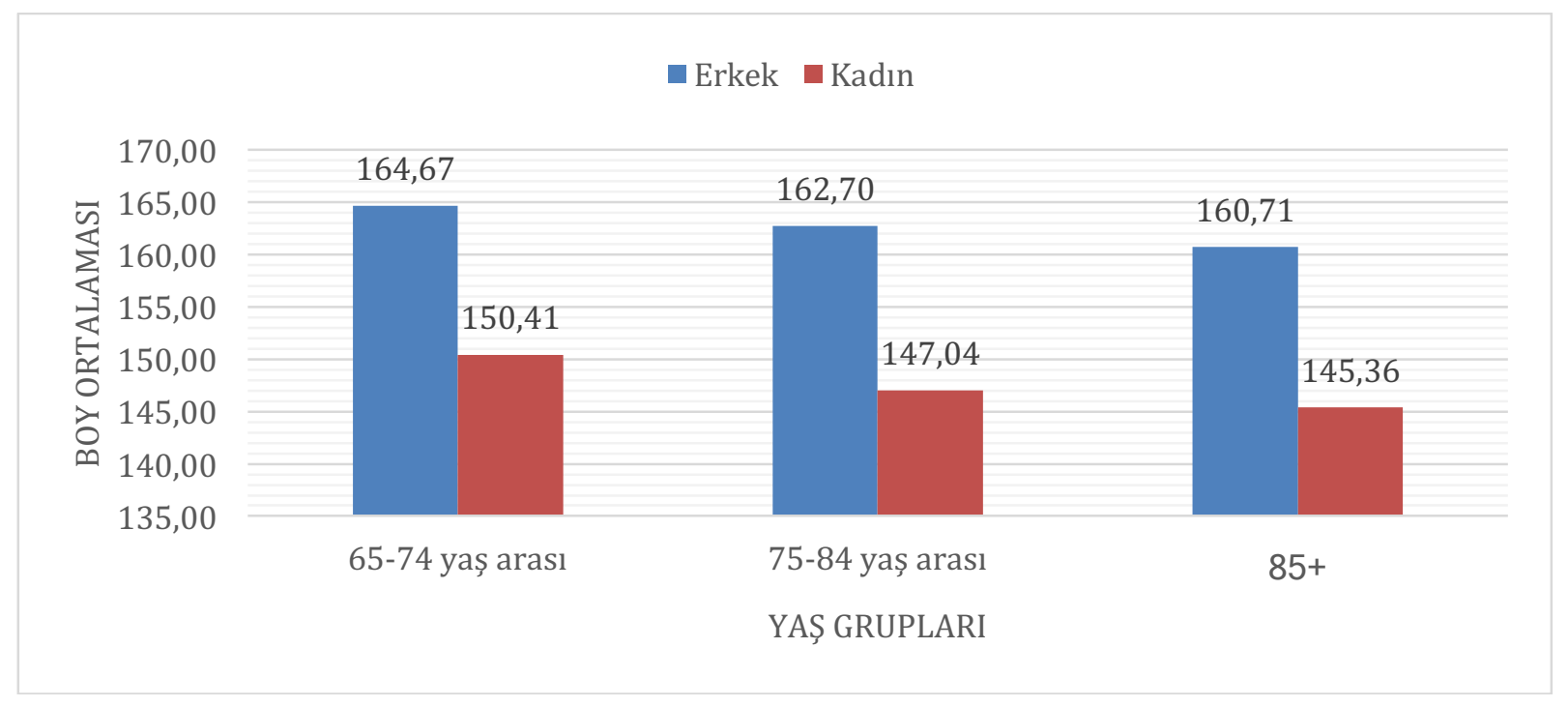

Şekil 2. Farklı Yaş Grupları Ve Cinsiyetlere Göre Katılımcıların Boy Ortalamaları

Şekil 2'de, tüm yaş aralıklarında erkeklerin boy ortalamasının kadınların boy ortalamasından daha yüksek olduğu görülmektedir.

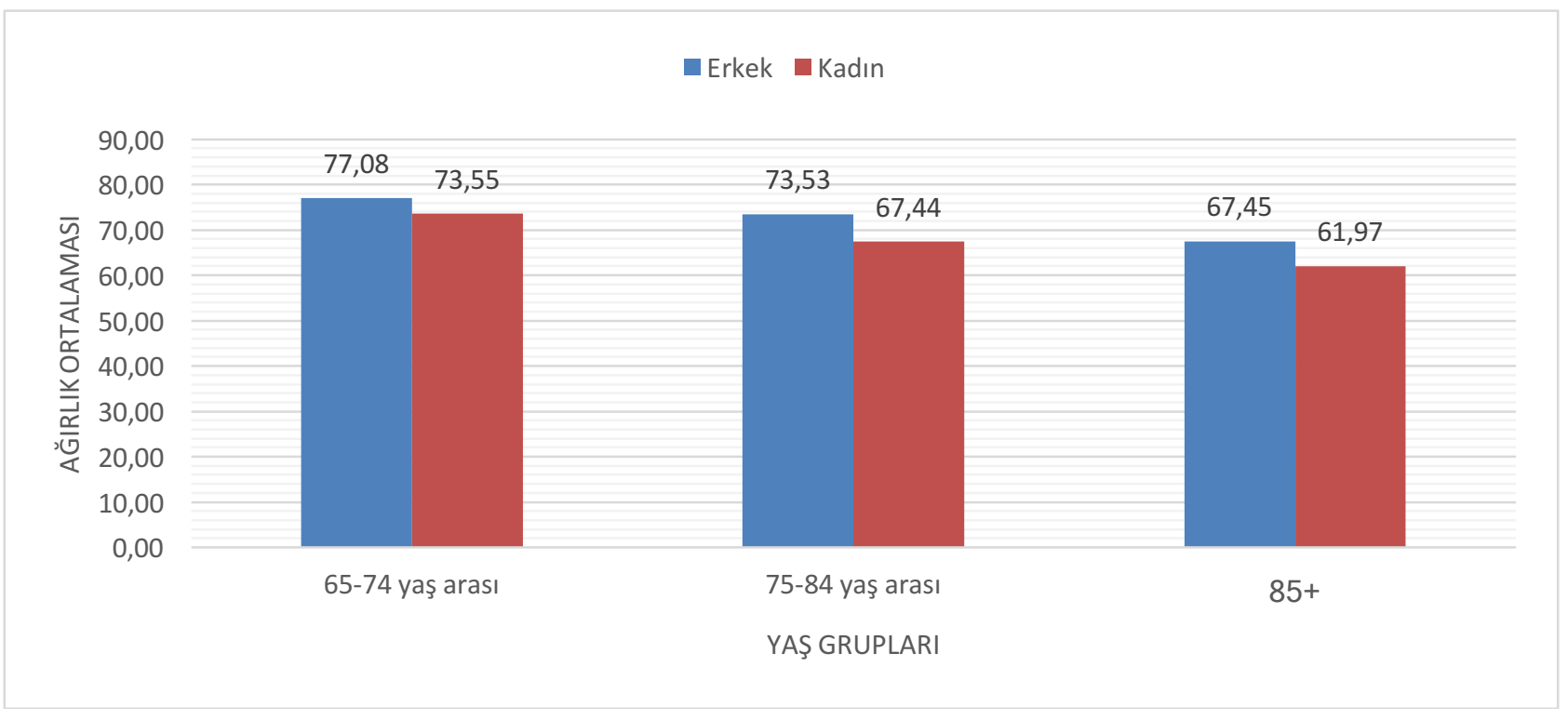

Şekil 3. Farklı Yaş Grupları Ve Cinsiyetlere Göre Katılımcıların Kilo Ortalamaları

Șekil 3'te ise tüm yaș gruplarında erkeklerin ağırlıklarının kadınlara göre daha fazla olduğu açıkça görülmektedir.

Çalışmaya katılan kişilerin antropometrik ölçümlerinin yapısı Tablo 1'deki sonuçlara bakılarak anlașılabilir. DK (\%) sonuçları değerlendirilirken așă̆ıgdaki kriterler göz önünde bulundurulmuștur. $(\mathrm{DK} \leq 5)$ ise küçük saçlım, $(6 \leq \mathrm{DK} \leq 15)$ ise ortalama bir saçlım, $(\mathrm{DK} \leq 16)$ ise büyük saçılım olduğunu gösterir. DK değeri en yüksek olan ölçümler kadınlarda oturma yeri dirsek yüksekliği $(23,40)$, kadınlarda ağırlık $(21,61)$, erkeklerde oturma yeri dirsek yüksekliği $(21,07)$, erkeklerde oturma yeri üst bacak yüksekliği $(20,41)$, erkeklerde ağırlık $(19,65)$ ve kadınlarda oturma yeri üst bacak yüksekliği $(18,06)$ 'dir. Bu değerler, genel olarak küçük olan diğer tüm boyutların DK değerlerini oldukça 
aşmıştır, yani en büyük saçılımlar bu ölçümlerdedir. DK değerlerinin büyük olması veride heterojen bir yapının yani değişkenliğin yüksek olduğunun göstergesidir. Dolayısıyla DK ne kadar büyükse tasarım kararları da o kadar zor olacaktır. Öte yandan en küçük DK değerleri kadınlarda kafa uzunluğu $(4,11)$, erkeklerde kafa uzunluğu $(4,13)$, erkekler için boy uzunluğu $(4,26)$, kadınlar için boy uzunluğu $(4,61)$ ve erkekler için ayakta omuz yüksekliği $(4,89)$ olup, en homojen veri yapısının bu boyutlarda olduğunu göstermektedir. DK\% değerlerini düşürmek için ortalama değerlerin arttırılması ve/veya örnekleme yeni gözlemler eklenerek elde edilecek standart sapma değerlerinin düşürülmesi gerekir. Örnek ortalamasının artırılması, sonuçta DK'nin azalmasına neden olacaktır. Bununla birlikte, SHO ile ilgili olarak, en yüksek SHO değerlerinin hem erkekler $(2,24)$ hem de kadınlar $(2,10)$ için ayakta göz yüksekliği değerleri olduğu bulunmuştur. Bu sonuçlara göre ayakta göz yüksekliği veri yapısının diğer ölçümlere göre daha heterojen olduğu söylenebilir. Heterojen veri yapısına sahip boyutlar ile örneklemden popülasyona yönelik genellemeler yapmak zor olabileceğinden analizler yapılırken dikkatli olunmalıdır. Çalışmaya katılan kişiler arasındaki genel ağırlık ortalamasının erkekler için $75,49 \mathrm{~kg}$ ve kadınlar için 70,51 kg olduğu görülmektedir. Katılımcıların genel boy ortalaması ise erkekler için $163,86 \mathrm{~cm}$ ve kadınlar için 148,85 cm'dir.

Tablo 1. Antropometrik Ölçümlerin Tanımlayıcı İstatistikleri

\begin{tabular}{|c|c|c|c|c|c|c|c|c|c|}
\hline \multirow{2}{*}{ Ölçüm Değişkenleri } & \multirow{2}{*}{ Cinsiyeti } & \multirow{2}{*}{$\mathrm{N}$} & \multirow{2}{*}{ Ort. } & \multirow{2}{*}{ SS } & \multirow{2}{*}{ SHO } & \multirow{2}{*}{$\mathrm{DK} \%$} & \multicolumn{3}{|c|}{ Yüzdelikler } \\
\hline & & & & & & & $5 \%$ & $50 \%$ & $95 \%$ \\
\hline \multirow{2}{*}{ Ağırlık (kg) } & Kadın & 1530 & 70,51 & 15,24 & 0,39 & 21,61 & 47,16 & 68,90 & 96,99 \\
\hline & Erkek & 1191 & 75,49 & 14,83 & 0,43 & 19,65 & 52,00 & 74,60 & 99,78 \\
\hline \multirow{2}{*}{ Boy uzunluğu (cm) } & Kadın & 1530 & 148,85 & 6,87 & 0,18 & 4,61 & 136,90 & 149,10 & 160,00 \\
\hline & Erkek & 1191 & 163,86 & 6,97 & 0,20 & 4,26 & 152,40 & 164,00 & 174,94 \\
\hline \multirow{2}{*}{ Alt Taraf Uzunluğu } & Kadın & 1530 & 790,05 & 60,13 & 1,54 & 7,61 & 703,00 & 782,00 & 892,00 \\
\hline & Erkek & 1191 & 872,73 & 59,45 & 1,72 & 6,81 & 773,00 & 871,00 & 968,40 \\
\hline \multirow{2}{*}{$\begin{array}{l}\text { Ayakta Göz } \\
\text { Yüksekliği }\end{array}$} & Kadın & 1530 & 1369,16 & 81,99 & 2,10 & 5,99 & 1223,00 & 1375,00 & 1490,45 \\
\hline & Erkek & 1191 & 1514,85 & 77,19 & 2,24 & 5,10 & 1392,00 & 1518,00 & 1633,00 \\
\hline \multirow{2}{*}{$\begin{array}{l}\text { Suprastrenal } \\
\text { Yükseklik }\end{array}$} & Kadın & 1530 & 1204,95 & 70,86 & 1,81 & 5,88 & 1076,00 & 1211,00 & 1313,45 \\
\hline & Erkek & 1191 & 1343,29 & 68,73 & 1,99 & 5,12 & 1232,00 & 1344,00 & 1452,00 \\
\hline \multirow{2}{*}{$\begin{array}{l}\text { Ayakta Omuz } \\
\text { Yüksekliği }\end{array}$} & Kadın & 1530 & 1245,82 & 68,61 & 1,75 & 5,51 & 1125,00 & 1250,00 & 1352,00 \\
\hline & Erkek & 1191 & 1386,98 & 67,85 & 1,97 & 4,89 & 1280,00 & 1387,00 & 1495,80 \\
\hline \multirow{2}{*}{$\begin{array}{l}\text { Sirt Parmak Ucu } \\
\text { Uzunluğu }\end{array}$} & Kadın & 1530 & 728,75 & 47,89 & 1,22 & 6,57 & 647,00 & 732,00 & 798,00 \\
\hline & Erkek & 1191 & 808,50 & 46,69 & 1,35 & 5,78 & 728,00 & 808,00 & 883,00 \\
\hline \multirow{2}{*}{ Tüm Kol Uzunluğu } & Kadin & 1530 & 637,43 & 47,67 & 1,22 & 7,48 & 559,10 & 638,00 & 714,90 \\
\hline & Erkek & 1191 & 716,73 & 48,10 & 1,39 & 6,71 & 638,00 & 716,00 & 797,40 \\
\hline \multirow{2}{*}{$\begin{array}{l}\text { Dirsek Parmak Ucu } \\
\text { Uzunluğu }\end{array}$} & Kadın & 1530 & 396,66 & 26,75 & 0,68 & 6,74 & 356,00 & 398,00 & 433,90 \\
\hline & Erkek & 1191 & 434,36 & 25,39 & 0,74 & 5,84 & 396,60 & 436,00 & 470,00 \\
\hline \multirow{2}{*}{ Üst Kol Uzunluğu } & Kadın & 1530 & 318,38 & 31,11 & 0,80 & 9,77 & 268,00 & 317,00 & 371,45 \\
\hline & Erkek & 1191 & 352,32 & 32,14 & 0,93 & 9,12 & 301,60 & 351,00 & 406,00 \\
\hline \multirow[b]{2}{*}{ Ön Kol Uzunluğu } & Kadın & 1530 & 197,70 & 18,77 & 0,48 & 9,49 & 172,00 & 197,00 & 223,45 \\
\hline & Erkek & 1191 & 212,43 & 18,97 & 0,55 & 8,93 & 187,60 & 212,00 & 240,00 \\
\hline Gögüs Derinliği & Kadın & 1530 & 239,37 & 28,10 & 0,72 & 11,74 & 196,00 & 238,00 & 286,00 \\
\hline
\end{tabular}




\begin{tabular}{|c|c|c|c|c|c|c|c|c|c|}
\hline & Erkek & 1191 & 245,50 & 28,23 & 0,82 & 11,50 & 198,00 & 245,00 & 292,00 \\
\hline \multirow{2}{*}{ Gögüs Genişliği } & Kadın & 1529 & 254,35 & 33,76 & 0,86 & 13,27 & 203,00 & 252,00 & 311,50 \\
\hline & Erkek & 1191 & 279,28 & 28,44 & 0,82 & 10,18 & 233,60 & 280,00 & 322,00 \\
\hline \multirow{2}{*}{ Omuz Genişliği } & Kadın & 1530 & 371,73 & 30,30 & 0,77 & 8,15 & 326,00 & 372,00 & 422,00 \\
\hline & Erkek & 1191 & 407,18 & 28,73 & 0,83 & 7,06 & 362,60 & 408,00 & 454,00 \\
\hline \multirow{2}{*}{ Kafa Uzunluğu } & Kadın & 1530 & 180,05 & 7,41 & 0,19 & 4,11 & 168,00 & 180,00 & 193,00 \\
\hline & Erkek & 1191 & 188,02 & 7,77 & 0,23 & 4,13 & 175,00 & 188,00 & 202,00 \\
\hline \multirow{2}{*}{ Büst Yüksekliği } & Kadın & 1530 & 772,57 & 51,88 & 1,33 & 6,72 & 683,00 & 774,50 & 854,45 \\
\hline & Erkek & 1191 & 843,39 & 49,92 & 1,45 & 5,92 & 752,00 & 848,00 & 921,40 \\
\hline \multirow{2}{*}{$\begin{array}{l}\text { Otururken Göz } \\
\text { Yüksekliği }\end{array}$} & Kadın & 1530 & 671,38 & 52,25 & 1,34 & 7,78 & 578,00 & 673,00 & 752,00 \\
\hline & Erkek & 1191 & 733,97 & 51,97 & 1,51 & 7,08 & 643,00 & 738,00 & 815,00 \\
\hline \multirow{2}{*}{$\begin{array}{l}\text { Otururken Omuz } \\
\text { Yüksekliği }\end{array}$} & Kadın & 1530 & 533,76 & 45,07 & 1,15 & 8,44 & 458,00 & 534,50 & 603,00 \\
\hline & Erkek & 1191 & 590,67 & 44,17 & 1,28 & 7,48 & 512,60 & 592,00 & 661,40 \\
\hline \multirow{2}{*}{$\begin{array}{l}\text { Otururken Kalça } \\
\text { Diz Uzunluğu }\end{array}$} & Kadın & 1528 & 536,35 & 33,94 & 0,87 & 6,33 & 482,00 & 537,00 & 592,00 \\
\hline & Erkek & 1191 & 564,78 & 32,19 & 0,93 & 5,70 & 512,00 & 565,00 & 616,00 \\
\hline \multirow{2}{*}{$\begin{array}{l}\text { Otururken } \\
\text { Popliteal Uzunluk }\end{array}$} & Kadın & 1528 & 460,69 & 31,49 & 0,81 & 6,84 & 408,00 & 463,00 & 510,55 \\
\hline & Erkek & 1191 & 478,38 & 30,45 & 0,88 & 6,37 & 427,60 & 476,00 & 527,00 \\
\hline \multirow{2}{*}{$\begin{array}{l}\text { Üst Bacak } \\
\text { Uzunluğu }\end{array}$} & Kadın & 1528 & 488,86 & 30,89 & 0,79 & 6,32 & 436,45 & 490,00 & 541,00 \\
\hline & Erkek & 1191 & 507,53 & 31,31 & 0,91 & 6,17 & 458,00 & 507,00 & 562,00 \\
\hline \multirow{2}{*}{$\begin{array}{l}\text { Otururken Diz } \\
\text { Yüksekliği }\end{array}$} & Kadın & 1527 & 506,79 & 29,60 & 0,76 & 5,84 & 457,00 & 510,00 & 551,00 \\
\hline & Erkek & 1191 & 539,59 & 27,38 & 0,79 & 5,07 & 497,00 & 540,00 & 583,00 \\
\hline \multirow{2}{*}{$\begin{array}{l}\text { Otururken Diz Altı } \\
\text { Yüksekliği }\end{array}$} & Kadın & 1527 & 417,71 & 25,22 & 0,65 & 6,04 & 380,00 & 418,00 & 453,00 \\
\hline & Erkek & 1191 & 440,30 & 25,15 & 0,73 & 5,71 & 403,00 & 440,00 & 480,00 \\
\hline \multirow{2}{*}{$\begin{array}{l}\text { Oturma Yeri Dirsek } \\
\text { Yüksekliği }\end{array}$} & Kadın & 1529 & 164,23 & 37,83 & 0,97 & 23,04 & 121,00 & 157,00 & 227,50 \\
\hline & Erkek & 1191 & 180,45 & 38,03 & 1,10 & 21,07 & 130,00 & 173,00 & 251,00 \\
\hline \multirow{2}{*}{$\begin{array}{l}\text { Otururken Kalça } \\
\text { Genişliği }\end{array}$} & Kadın & 1530 & 344,27 & 35,75 & 0,91 & 10,38 & 286,00 & 343,00 & 403,00 \\
\hline & Erkek & 1191 & 340,82 & 30,73 & 0,89 & 9,02 & 292,00 & 340,00 & 391,00 \\
\hline \multirow{2}{*}{$\begin{array}{l}\text { Oturma Yeri Üst } \\
\text { Bacak Yüksekliği }\end{array}$} & Kadın & 1527 & 105,12 & 18,99 & 0,49 & 18,06 & 75,40 & 103,00 & 140,00 \\
\hline & Erkek & 1191 & 119,33 & 24,36 & 0,71 & 20,41 & 87,00 & 115,00 & 162,40 \\
\hline \multirow{2}{*}{ Alt Bacak Uzunluğu } & Kadın & 1527 & 320,44 & 28,08 & 0,72 & 8,76 & 273,80 & 320,00 & 366,00 \\
\hline & Erkek & 1191 & 340,83 & 24,33 & 0,71 & 7,14 & 300,00 & 342,00 & 381,00 \\
\hline \multirow{2}{*}{ Kalça Genişliği } & Kadın & 1529 & 333,00 & 28,34 & 0,72 & 8,51 & 290,00 & 333,00 & 380,50 \\
\hline & Erkek & 1191 & 331,05 & 23,74 & 0,69 & 7,17 & 294,00 & 331,00 & 370,00 \\
\hline \multirow{2}{*}{ Basen Genişliği } & Kadın & 1529 & 333,36 & 27,47 & 0,70 & 8,24 & 291,00 & 333,00 & 380,00 \\
\hline & Erkek & 1191 & 331,31 & 23,06 & 0,67 & 6,96 & 295,00 & 331,00 & 368,00 \\
\hline \multirow{2}{*}{ Omuz Çevresi } & Kadın & 1530 & 103,18 & 8,32 & 0,21 & 8,07 & 90,00 & 103,00 & 117,64 \\
\hline & Erkek & 1191 & 109,49 & 7,76 & 0,22 & 7,08 & 97,00 & 109,00 & 122,20 \\
\hline Gögüs Çevresi & Kadın & 1529 & 93,41 & 9,09 & 0,23 & 9,73 & 79,00 & 93,00 & 108,65 \\
\hline
\end{tabular}




\begin{tabular}{|c|c|c|c|c|c|c|c|c|c|}
\hline & Erkek & 1191 & 97,10 & 8,47 & 0,25 & 8,72 & 82,50 & 97,20 & 111,00 \\
\hline \multirow{2}{*}{ Bel Çevresi } & Kadın & 1529 & 91,62 & 12,01 & 0,31 & 13,11 & 73,00 & 91,00 & 112,00 \\
\hline & Erkek & 1190 & 93,85 & 11,34 & 0,33 & 12,08 & 74,00 & 94,00 & 111,50 \\
\hline \multirow{2}{*}{ Karın Çevresi } & Kadın & 1527 & 104,46 & 12,13 & 0,31 & 11,61 & 85,04 & 104,00 & 124,00 \\
\hline & Erkek & 1188 & 99,37 & 11,27 & 0,33 & 11,34 & 82,00 & 98,50 & 118,50 \\
\hline \multirow{2}{*}{ Kalça Çevresi } & Kadın & 1528 & 100,80 & 12,21 & 0,31 & 12,11 & 84,00 & 100,00 & 121,00 \\
\hline & Erkek & 1190 & 96,52 & 8,52 & 0,25 & 8,83 & 83,00 & 96,35 & 110,34 \\
\hline \multirow{2}{*}{ Üst Uyluk Çevresi } & Kadın & 1527 & 50,68 & 6,82 & 0,17 & 13,46 & 40,00 & 50,00 & 62,38 \\
\hline & Erkek & 1191 & 49,04 & 6,64 & 0,19 & 13,55 & 38,50 & 48,70 & 60,00 \\
\hline \multirow{2}{*}{ Üst Kol Çevresi } & Kadın & 1529 & 25,66 & 3,91 & 0,10 & 15,24 & 19,90 & 25,50 & 32,35 \\
\hline & Erkek & 1191 & 24,64 & 3,38 & 0,10 & 13,74 & 19,00 & 24,50 & 30,00 \\
\hline \multirow{2}{*}{ Boyun Çevresi } & Kadın & 1530 & 32,60 & 2,86 & 0,07 & 8,78 & 28,00 & 32,20 & 37,50 \\
\hline & Erkek & 1191 & 36,04 & 3,31 & 0,10 & 9,19 & 31,00 & 36,00 & 41,50 \\
\hline \multirow{2}{*}{ Dirsek Genişliği } & Kadın & 1528 & 66,68 & 7,29 & 0,19 & 10,93 & 56,39 & 66,12 & 79,04 \\
\hline & Erkek & 1190 & 70,39 & 5,10 & 0,15 & 7,24 & 61,80 & 70,64 & 78,23 \\
\hline \multirow{2}{*}{ El Bilek Çevresi } & Kadın & 1530 & 14,88 & 1,82 & 0,05 & 12,24 & 13,00 & 15,00 & 17,00 \\
\hline & Erkek & 1191 & 15,99 & 1,48 & 0,04 & 9,26 & 14,00 & 16,00 & 18,10 \\
\hline \multirow{2}{*}{ El Uzunluğu } & Kadın & 1529 & 170,94 & 12,76 & 0,33 & 7,46 & 150,00 & 171,87 & 189,24 \\
\hline & Erkek & 1191 & 188,07 & 14,25 & 0,41 & 7,58 & 164,00 & 188,31 & 210,00 \\
\hline \multirow{2}{*}{ El Genişliği } & Kadın & 1530 & 74,57 & 4,54 & 0,12 & 6,09 & 67,38 & 74,72 & 81,49 \\
\hline & Erkek & 1191 & 82,82 & 4,88 & 0,14 & 5,89 & 74,90 & 82,84 & 91,00 \\
\hline \multirow{2}{*}{$\begin{array}{l}\text { Başparmak Ucu } \\
\text { Bilek Mesafesi }\end{array}$} & Kadın & 1530 & 98,77 & 12,48 & 0,32 & 12,64 & 76,55 & 100,21 & 117,29 \\
\hline & Erkek & 1191 & 104,32 & 13,14 & 0,38 & 12,59 & 81,83 & 105,22 & 123,69 \\
\hline \multirow{2}{*}{$\begin{array}{l}\text { El Başparmak } \\
\text { Uzunluğu }\end{array}$} & Kadın & 1530 & 53,01 & 7,54 & 0,19 & 14,21 & 41,13 & 52,87 & 65,54 \\
\hline & Erkek & 1191 & 56,91 & 7,82 & 0,23 & 13,75 & 44,13 & 56,73 & 69,50 \\
\hline \multirow{2}{*}{ Diz Genişliği } & Kadın & 1522 & 99,47 & 12,87 & 0,33 & 12,94 & 80,92 & 98,16 & 122,00 \\
\hline & Erkek & 1190 & 98,39 & 7,79 & 0,23 & 7,91 & 87,00 & 98,00 & 112,00 \\
\hline \multirow{2}{*}{ Diz Çevresi } & Kadın & 1522 & 36,48 & 4,25 & 0,11 & 11,65 & 30,00 & 36,00 & 44,00 \\
\hline & Erkek & 1189 & 36,23 & 3,55 & 0,10 & 9,80 & 31,00 & 36,00 & 42,00 \\
\hline \multirow{2}{*}{ Baldır Çevresi } & Kadın & 1523 & 30,89 & 4,43 & 0,11 & 14,34 & 24,00 & 31,00 & 38,10 \\
\hline & Erkek & 1188 & 31,43 & 4,10 & 0,12 & 13,06 & 25,00 & 31,00 & 38,16 \\
\hline \multirow{2}{*}{ Ayak Bileği Çevresi } & Kadın & 1518 & 21,08 & 2,76 & 0,07 & 13,11 & 17,00 & 21,00 & 26,00 \\
\hline & Erkek & 1189 & 21,64 & 2,52 & 0,07 & 11,64 & 18,00 & 21,10 & 26,00 \\
\hline \multirow{2}{*}{ Ayak Genişliği } & Kadın & 1525 & 86,66 & 6,45 & 0,17 & 7,44 & 76,82 & 86,21 & 98,00 \\
\hline & Erkek & 1191 & 93,19 & 6,46 & 0,19 & 6,94 & 82,99 & 93,00 & 104,00 \\
\hline \multirow{2}{*}{ Ayak Uzunluğu } & Kadın & 1527 & 225,18 & 12,04 & 0,31 & 5,35 & 204,00 & 225,40 & 244,08 \\
\hline & Erkek & 1191 & 247,77 & 13,39 & 0,39 & 5,40 & 226,95 & 248,00 & 270,00 \\
\hline
\end{tabular}


Antropometrik ölçümlerin kadın ve erkek katılımcılara göre farklılık gösterip göstermediği bağımsız örnekler için t-testi ile analiz edilir. T-testi sonuçları ile erkek ve kadın katılımcılar arasındaki bazı anlamlı farklılıklar Tablo 2'de gösterilmektedir. İki grup arasında anlamlı farklılık olduğu tespit edilen boyutlardan erkeklerin daha büyük değerlere sahip olduğu antropometrik ölçümler: ağırlık, boy uzunluğu, alt taraf uzunluğu, ayakta göz yüksekliği, suprastrenal yükseklik, ayakta omuz yüksekliği, sırt parmak ucu uzunluğu, tüm kol uzunluğu, dirsek parmak ucu, üst kol uzunluğu, ön kol uzunluğu, göğüs derinliği, gögüs genişliği, omuz genişliği, kafa uzunluğu, büst yüksekliği, otururken göz yüksekliği, otururken omuz yüksekliği, otururken kalça diz uzunluğu, otururken popliteal uzunluk, üst bacak uzunluğu, otururken diz yüksekliği, otururken diz altı yüksekliği, oturma yeri dirsek yüksekliği, oturma yeri üst bacak yüksekliği, alt bacak uzunluğu, omuz çevresi, göğüs çevresi, bel çevresi, boyun çevresi, dirsek genişliği, el bilek çevresi, el uzunluğu, el genişliği, başparmak ucu bilek mesafesi, el başparmak uzunluğu, baldır çevresi, ayak bileği çevresi, ayak genişliği, ayak uzunluğu biçimindedir. Anlamlı farklılıkları olan boyutlardan kadınların daha büyük değerlere sahip olduğu antropometrik ölçümler ise otururken kalça genişliği, basen genişliği, karın çevresi, kalça çevresi, üst uyluk çevresi, üst kol çevresi, diz genişliği olarak sıralanabilir. Öte yandan Tablo 2'ye göre kalça genişliği ve diz çevresi değerlerinin kadın ve erkek katılımcılar arasındaki farklarının istatistiksel olarak anlamlı olmadığı söylenebilir ( $p>0,05)$.

Tablo 2. Kadınlar ve Erkekler Arasındaki Antropometrik Farklılıklar

\begin{tabular}{|c|c|c|c|c|c|c|}
\hline Ölçüm Değişkenleri & Cinsiyeti & $\mathrm{N}$ & Ort. & SS & $\begin{array}{c}\text { t-testi } \\
\text { istatistiği }\end{array}$ & p-değeri \\
\hline \multirow{2}{*}{ Ağırlık } & Kadın & 1530 & 70,51 & 15,24 & \multirow{2}{*}{$-8,558$} & \multirow{2}{*}{0,000} \\
\hline & Erkek & 1191 & 75,49 & 14,83 & & \\
\hline \multirow{2}{*}{ Boy Uzunluğu cm } & Kadın & 1530 & 148,85 & 6,87 & \multirow{2}{*}{$-56,194$} & \multirow{2}{*}{0,000} \\
\hline & Erkek & 1191 & 163,86 & 6,97 & & \\
\hline \multirow{2}{*}{ Alt Taraf Uzunluğu } & Kadın & 1530 & 790,05 & 60,13 & \multirow{2}{*}{$-35,756$} & \multirow{2}{*}{0,000} \\
\hline & Erkek & 1191 & 872,73 & 59,45 & & \\
\hline \multirow{2}{*}{ Ayakta Göz Yüksekliği } & Kadın & 1530 & 1369,16 & 81,99 & \multirow{2}{*}{$-47,174$} & \multirow{2}{*}{0,000} \\
\hline & Erkek & 1191 & 1514,85 & 77,19 & & \\
\hline \multirow{2}{*}{ Suprastrenal Yükseklik } & Kadın & 1530 & 1204,95 & 70,86 & \multirow{2}{*}{$-51,189$} & \multirow{2}{*}{0,000} \\
\hline & Erkek & 1191 & 1343,29 & 68,73 & & \\
\hline \multirow{2}{*}{ Ayakta Omuz Yüksekliği } & Kadın & 1530 & 1245,82 & 68,61 & \multirow{2}{*}{$-53,504$} & \multirow{2}{*}{0,000} \\
\hline & Erkek & 1191 & 1386,98 & 67,85 & & \\
\hline \multirow{2}{*}{$\begin{array}{l}\text { Sirt Parmak Ucu } \\
\text { Uzunluğu }\end{array}$} & Kadın & 1530 & 728,75 & 47,89 & \multirow{2}{*}{$-43,561$} & \multirow{2}{*}{0,000} \\
\hline & Erkek & 1191 & 808,50 & 46,69 & & \\
\hline \multirow{2}{*}{ Tüm Kol Uzunluğu } & Kadın & 1530 & 637,43 & 47,67 & \multirow{2}{*}{$-42,878$} & \multirow{2}{*}{0,000} \\
\hline & Erkek & 1191 & 716,73 & 48,10 & & \\
\hline \multirow{2}{*}{$\begin{array}{l}\text { Dirsek Parmak Ucu } \\
\text { Uzunluğu }\end{array}$} & Kadın & 1530 & 396,66 & 26,75 & \multirow{2}{*}{$-37,288$} & \multirow{2}{*}{0,000} \\
\hline & Erkek & 1191 & 434,36 & 25,39 & & \\
\hline \multirow{2}{*}{ Üst Kol Uzunluğu } & Kadın & 1530 & 318,38 & 31,11 & \multirow{2}{*}{$-27,821$} & \multirow{2}{*}{0,000} \\
\hline & Erkek & 1191 & 352,32 & 32,14 & & \\
\hline \multirow{2}{*}{ Ön Kol Uzunluğu } & Kadın & 1530 & 197,70 & 18,77 & \multirow{2}{*}{$-20,216$} & \multirow{2}{*}{0,000} \\
\hline & Erkek & 1191 & 212,43 & 18,97 & & \\
\hline Gögüs Derinliği & Kadın & 1530 & 239,37 & 28,10 & $-5,634$ & 0,000 \\
\hline
\end{tabular}




\begin{tabular}{|c|c|c|c|c|c|c|}
\hline & Erkek & 1191 & 245,50 & 28,23 & & \\
\hline \multirow{2}{*}{ Gögüs Genişliği } & Kadın & 1529 & 254,35 & 33,76 & \multirow{2}{*}{$-20,453$} & \multirow{2}{*}{0,000} \\
\hline & Erkek & 1191 & 279,28 & 28,44 & & \\
\hline \multirow{2}{*}{ Omuz Genişliği } & Kadın & 1530 & 371,73 & 30,30 & \multirow{2}{*}{$-30,972$} & \multirow{2}{*}{0,000} \\
\hline & Erkek & 1191 & 407,18 & 28,73 & & \\
\hline \multirow{2}{*}{ Kafa Uzunluğu } & Kadın & 1530 & 180,05 & 7,41 & \multirow{2}{*}{$-27,232$} & \multirow{2}{*}{0,000} \\
\hline & Erkek & 1191 & 188,02 & 7,77 & & \\
\hline \multirow{2}{*}{ Büst Yüksekliği } & Kadın & 1530 & 772,57 & 51,88 & \multirow{2}{*}{$-35,912$} & \multirow{2}{*}{0,000} \\
\hline & Erkek & 1191 & 843,39 & 49,92 & & \\
\hline \multirow{2}{*}{$\begin{array}{l}\text { Otururken Göz } \\
\text { Yüksekliği }\end{array}$} & Kadın & 1530 & 671,38 & 52,25 & \multirow{2}{*}{$-31,072$} & \multirow{2}{*}{0,000} \\
\hline & Erkek & 1191 & 733,97 & 51,97 & & \\
\hline \multirow{2}{*}{$\begin{array}{l}\text { Otururken Omuz } \\
\text { Yüksekliği }\end{array}$} & Kadın & 1530 & 533,76 & 45,07 & \multirow{2}{*}{$-32,968$} & \multirow{2}{*}{0,000} \\
\hline & Erkek & 1191 & 590,67 & 44,17 & & \\
\hline \multirow{2}{*}{$\begin{array}{l}\text { Otururken Kalça Diz } \\
\text { Uzunluğu }\end{array}$} & Kadın & 1528 & 536,35 & 33,94 & \multirow{2}{*}{$-22,161$} & \multirow{2}{*}{0,000} \\
\hline & Erkek & 1191 & 564,78 & 32,19 & & \\
\hline \multirow{2}{*}{$\begin{array}{l}\text { Otururken Popliteal } \\
\text { Uzunluk }\end{array}$} & Kadın & 1528 & 460,69 & 31,49 & \multirow{2}{*}{$-14,749$} & \multirow{2}{*}{0,000} \\
\hline & Erkek & 1191 & 478,38 & 30,45 & & \\
\hline \multirow{2}{*}{ Üst Bacak Uzunluğu } & Kadın & 1528 & 488,86 & 30,89 & \multirow{2}{*}{$-15,540$} & \multirow{2}{*}{0,000} \\
\hline & Erkek & 1191 & 507,53 & 31,31 & & \\
\hline & Kadın & 1527 & 506,79 & 29,60 & & \\
\hline 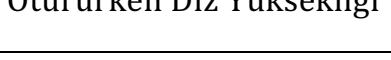 & Erkek & 1191 & 539,59 & 27,38 & $-29,011$ & 0,000 \\
\hline Otururken Diz Altı & Kadın & 1527 & 417,71 & 25,22 & 20 202 & 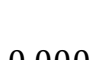 \\
\hline Yüksekliği & Erkek & 1191 & 440,30 & 25,15 & $-23,203$ & 0,000 \\
\hline Oturma Yeri Dirsek & Kadın & 1529 & 164,23 & 37,83 & $190<7$ & (2) \\
\hline Yüksekliği & Erkek & 1191 & 180,45 & 38,03 & $-11,00 /$ & 0,000 \\
\hline Otururken Kalça & Kadın & 1530 & 344,27 & 35,75 & 2654 & $0 \Omega 0$ \\
\hline Genişliği & Erkek & 1191 & 340,82 & 30,73 & 2,034 & 0,000 \\
\hline Oturma Yeri Üst Bacak & Kadin & 1527 & 105,12 & 18,99 & $1700 \mathrm{r}$ & 000 \\
\hline Yüksekliği & Erkek & 1191 & 119,33 & 24,36 & $-17,096$ & 0,000 \\
\hline 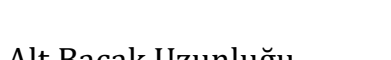 & Kadin & 1527 & 320,44 & 28,08 & 10002 & مחمחم \\
\hline Al Басак Uzumugu & Erkek & 1191 & 340,83 & 24,33 & $-19,902$ & 0,000 \\
\hline 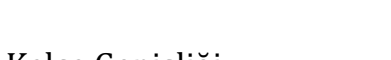 & Kadın & 1529 & 333,00 & 28,34 & 1011 & 0056 \\
\hline Kalça Genişıgi & Erkek & 1191 & 331,05 & 23,74 & 1,911 & 0,056 \\
\hline & Kadın & 1529 & 333,36 & 27,47 & 0070 & 0020 \\
\hline Basen Genışlıgı & Erkek & 1191 & 331,31 & 23,06 & 2,078 & 0,038 \\
\hline Omun Counci & Kadın & 1530 & 103,18 & 8,32 & 20000 & 000 \\
\hline Umuz çevrest & Erkek & 1191 & 109,49 & 7,76 & $-20,200$ & 0,000 \\
\hline Gögüs Çevresi & Kadın & 1529 & 93,41 & 9,09 & $-10,846$ & 0,000 \\
\hline
\end{tabular}




\begin{tabular}{|c|c|c|c|c|c|c|}
\hline & Erkek & 1191 & 97,10 & 8,47 & & \\
\hline \multirow{2}{*}{ Bel Çevresi } & Kadın & 1529 & 91,62 & 12,01 & \multirow{2}{*}{$-4,924$} & \multirow{2}{*}{0,000} \\
\hline & Erkek & 1190 & 93,85 & 11,34 & & \\
\hline \multirow{2}{*}{ Karın Çevresi } & Kadın & 1527 & 104,46 & 12,13 & \multirow{2}{*}{11,195} & \multirow{2}{*}{0,000} \\
\hline & Erkek & 1188 & 99,37 & 11,27 & & \\
\hline \multirow{2}{*}{ Kalça Çevresi } & Kadın & 1528 & 100,80 & 12,21 & \multirow{2}{*}{10,290} & \multirow{2}{*}{0,000} \\
\hline & Erkek & 1190 & 96,52 & 8,52 & & \\
\hline \multirow{2}{*}{ Üst Uyluk Çevresi } & Kadın & 1527 & 50,68 & 6,82 & \multirow{2}{*}{6,308} & \multirow{2}{*}{0,000} \\
\hline & Erkek & 1191 & 49,04 & 6,64 & & \\
\hline \multirow{2}{*}{ Üst Kol Çevresi } & Kadın & 1529 & 25,66 & 3,91 & \multirow{2}{*}{7,214} & \multirow{2}{*}{0,000} \\
\hline & Erkek & 1191 & 24,64 & 3,38 & & \\
\hline \multirow{2}{*}{ Boyun Çevresi } & Kadın & 1530 & 32,60 & 2,86 & \multirow{2}{*}{$-29,056$} & \multirow{2}{*}{0,000} \\
\hline & Erkek & 1191 & 36,04 & 3,31 & & \\
\hline \multirow{2}{*}{ Dirsek Genişliği } & Kadın & 1528 & 66,68 & 7,29 & \multirow{2}{*}{$-14,935$} & \multirow{2}{*}{0,000} \\
\hline & Erkek & 1190 & 70,39 & 5,10 & & \\
\hline \multirow{2}{*}{ El Bilek Çevresi } & Kadın & 1530 & 14,88 & 1,82 & \multirow{2}{*}{$-17,123$} & \multirow{2}{*}{0,000} \\
\hline & Erkek & 1191 & 15,99 & 1,48 & & \\
\hline \multirow{2}{*}{ El Uzunluğu } & Kadın & 1529 & 170,94 & 12,76 & \multirow{2}{*}{$-33,009$} & \multirow{2}{*}{0,000} \\
\hline & Erkek & 1191 & 188,07 & 14,25 & & \\
\hline 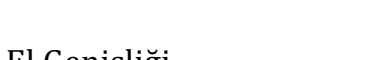 & Kadın & 1530 & 74,57 & 4,54 & 15510 & 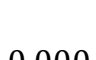 \\
\hline Ll uemişıgı & Erkek & 1191 & 82,82 & 4,88 & $-45,510$ & 0,000 \\
\hline Başparmak Ucu Bilek & Kadın & 1530 & 98,77 & 12,48 & 11255 & $0 \Omega 0$ \\
\hline Mesafesi & Erkek & 1191 & 104,32 & 13,14 & $-11,255$ & 0,000 \\
\hline Cl Posnorm & Kadın & 1530 & 53,01 & 7,54 & 12102 & 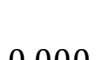 \\
\hline Li Daşpaititan Uzuntugu & Erkek & 1191 & 56,91 & 7,82 & 10,102 & 0,000 \\
\hline & Kadın & 1522 & 99,47 & 12,87 & & \\
\hline Dlz Genışligl & Erkek & 1190 & 98,39 & 7,79 & 2,535 & 0,011 \\
\hline & Kadın & 1522 & 36,48 & 4,25 & 1612 & 0107 \\
\hline DIZ çeviesi & Erkek & 1189 & 36,23 & 3,55 & 1,012 & 0,107 \\
\hline Doldun Coumbi & Kadın & 1523 & 30,89 & 4,43 & & \\
\hline Daluir Çevrest & Erkek & 1188 & 31,43 & 4,10 & $-3,2 / 1$ & 0,001 \\
\hline 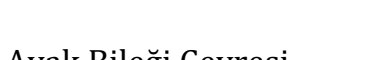 & Kadın & 1518 & 21,08 & 2,76 & -5384 & 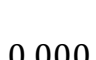 \\
\hline Ayak Bilegi çevresi & Erkek & 1189 & 21,64 & 2,52 & $-5,304$ & 0,000 \\
\hline A unl Conicliŭi & Kadın & 1525 & 86,66 & 6,45 & & \\
\hline Ауак Genışigi & Erkek & 1191 & 93,19 & 6,46 & $-20,130$ & 0,000 \\
\hline & Kadın & 1527 & 225,18 & 12,04 & & \\
\hline Ryan uzumugu & Erkek & 1191 & 247,77 & 13,39 & $-46,209$ & 0,000 \\
\hline
\end{tabular}




\section{Sonuçlar ve Tartışma}

Yaşlı bireylerden alınan antropometrik ölçümlerin, yaşlı bireylerin kullandığ ${ }_{1}$ iç-dış mekanların ergonomik tasarımı ile mutfak eşyaları ve mobilyalarının tasarımına yardımcı olabileceği bildirilmektedir (Molenbroek, 1987; Kirvesoja vd., 2000; Kothiyal ve Tetty, 2000; Kaewdok, 2020). Antropometrik değerlerinin bilinmesinin; bireylerin değişen vücut bileşimleri ve ona bağlı sağlık problemlerini ortaya koymada da önemli olacağl bildirilmektedir (Silva Coqueiro vd., 2009). Yapılan çalışma sonuçlarına göre; antropometrik değerler belirgin cinsiyet farklılıklarına sahiptir. Bunun sebebi kuşkusuz, kadın ve erkek bireylerin farklı fiziksel özelliklere sahip olmasıdır.

Yaşlı bireyin hayatını ve günlük aktivitelerini güvenli hale getirmek ve kolaylaştırmak, kişisel emniyet açısından güvenli yaşam kalitesi sunmak, sağlık, fiziksel, zihinsel, sosyal kapasite ve durumlarını iyileştirmek, geliştirmek, kısaca sağlıklı yaşlanmanın sağlanması ve devam ettirilmesi için ürünler ve tasarımlar geliştirmek, sunmak ve değerlendirmek önemlidir. Yaşlı bireylerin, yaşamlarının çoğunu mekân içinde geçirmeleri nedeni ile yaşanılan mekânda nitelik ve kolaylık aranmaktadır. Bununla birlikte iç mekânda yer alan birçok araç gereç yaşlıların kullanımı için uygun değildir. Yaşlıların çoğu musluk, kapı kolu, aydınlatma düğmesi, küvet, klozet ve raflara kolayca erişememekte veya kolayca kullanamamaktadır. Bu nedenle banyo, mutfak, yatak odası, oturma odası, girişler, aydınlatma, merdiven, tutamaklar ve bunun gibi yapılar için yaşlı bireyin yaşamına uygun tasarım önerileri ve uygulamaları gerekmektedir (Akın, 2012; Al-Ansari ve Mokdad, 2015; Kalınkara, 2016; Kalınkara, 2015).

Ülkemizde yaşlı birey üzerine yapılan antropometrik çalışmaların sayısının ve kapsamının yetersizliği bilinen bir gerçektir (Akın, 2006; Atamtürk, 2010; Kalınkara, 2016). Ülkemizde ileri yaş bireyleri üzerinde, özellikle 65 yaş ve yukarısı nüfusu hedef alan kapsamlı bir antropometrik çalışma bulunmamaktadır; yapılan az sayıda çalışma daha çok dar kapsamlı ve yerel düzeyde olup, Türkiye yaşlı nüfusu konusunda antropometrik değerler açısından genel bir bilgi sunmaktan uzaktır (Bağcı Bosi, 2003; Gültekin ve Akın, 2005; Aslan vd., 2006; Yardımcı ve Özçelik, 2006; Ersoy Öztürkler, 2009; Atamtürk, 2010; Atamtürk ve Göçmen Mas, 2010; Aktan Korkmaz, 2013; Aktan Korkmaz ve Özgün Başıbüyük, 2013). Türkiye genelini ele alan kapsamlı tek antropometrik araştırma 2005 yılında Güleç ve arkadaşlarının yaptığı, örneklemini 20-65 yaş arası bireylerin oluşturduğu Anadolu popülasyonunun antropometrik boyutlarını ortaya koyan ve ergonomik, endüstriyel, spor çalışmaları için temel veri oluşturan BAP ve TUBİTAK ortaklı projedir (Güleç vd., 2009). Alanda bulunan bu boşluğu doldurmak amacıyla yapmış olduğumuz TÜBİTAK 115M548 no'lu "Anadolu Yaşlılarının Antropometrik Boyutları" isimli 1001 Projesi neticesindeki verilerden bu çalışmamızda sunduklarımız kapsamında, yaşlılara yönelik birçok çalışma alanı için; özellikle de ergonomi, beslenme, fizyoterapi ve gerontoloji alanlarında temel kaynak olması hedeflenmektedir.

Başarılı yaşlanmanın temelinde, bireyin bağımsızlığını sürdürmesi ve yerinde yaşlanması söz konusudur. Yaşlı birey; fiziksel gücünün ve yeterliliklerinin azaldığı durumlarda onu yönlendirecek ve işini kolaylaştıracak destek araçlarına ihtiyaç duyar. Bu çalışmada sunulan antropometrik veriler ve öneriler doğrultusunda oluşturulacak ve uygulanacak yaşlı odaklı iç-dış mekân ve alet tasarımlarının yașama katılımı pozitif yönde etkilemesi, başarılı ve aktif yaşlanma imkânını sağlaması hedeflenmektedir.

\section{Teșekkür}

$\mathrm{Bu}$ çalışma TÜBİTAK tarafından 115M548 no'lu "Anadolu Yaşlılarının Antropometrik Boyutları" isimli 1001 Projesi kapsamında desteklenmiştir.

\section{Çıkar Çatışması}

Yazarlar tarafından herhangi bir çıkar çatışması beyan edilmemiștir.

\section{Kaynaklar}

Akın, G. (2006). Her Yönüyle Yaşlılık, Palme Yayıncılık: Ankara.

Akın, G. (2012). Ergonomi (1. Basım). Ankara: Tiydem Yayıncılık.

Akkaya Kozak, D., Bahar, N. T., Ay, F., Kılıç, B. \& Özgün Başıbüyük, G. (2021). Türkiye'de İleri Yaştaki Yetişkinlerin Düşme Durumları. Antropoloji, (41), 11-20. DOI: 10.33613/antropolojidergisi.810773

Aktan Korkmaz, B. (2013). Sivas İl Merkezi Orta ve İleri Yaş Bireylerinin Antropometrik Ölçümlerinin Değerlendirilmesi ve Medikal Aparat Tasarım Uygulaması, Yüksek Lisans Tezi, Sivas.

Aktan Korkmaz, B. ve Özgün Başıbüyük, G. (2013). "Sivas İli 50 Yaş ve Üzeri Bireylerinde Obezite", Antropoloji Dergisi, 26: 55-72.

Al-Ansari, M. S., \& Mokdad, M. (2015). Elderly Anthropometrics for Ergonomic Purposes. Journal of Educational \& Psychological Sciences, 16(1), 605-632. doi:10.12785/JEPS/160120. 
Aslan D., Özcebe H., Takmaz S., Topatan S., Şahin A., Arıkan M., Tanrıverdi B. (2006). Ankara'da Bir Sağlık Ocağı Bölgesinde Yaşayan 65 Yaş ve Üzeri Bireylerin Antropometrik Ölçümlerinin Değerlendirilmesi. Turkish Journal of Geriatrics, 9(2): 65- 69.

Atamtürk, D. (2010). Orta ve İleri Yaştaki Bireylerin Antropometrik Ölçülerinde Yaşa Bağlı Olarak Meydana Gelen Değişimler. Geriatri ve Geriatrik Nöropsi.

Atamtürk, D., Göçmen Mas, N. (2010). Elli Yaș ve Üzerindeki Bireylerde Malnütrisyon ve Obezite Sıklığı. Geriatri ve Geriatrik Nöropsikiyatri, 2(1): 17.kiyatri, 1(3): 13-22.

Aydıner Boylu, A. (2013). Yaşlılıkta Yaşam Kalitesi ve Konut İlișkisi. Toplum ve Sosyal Hizmet, 24 (1), 145-156. Retrieved from https://dergipark.org.tr/tr/pub/tsh/issue/4841 $\underline{0 / 613381}$.

Bağcl Bosi, T. (2003). Yaşlılarda Antropometri. Turkish Journal of Geriatrics, 6(4), 147-151.

Dianat I, Molenbroek J, Castellucci HI. (2018). A Review of The Methodology and Applications of Anthropometry in Ergonomics and Product Design. Ergonomics. Dec;61(12):1696-1720. doi: 10.1080/00140139.2018.1502817. Nov 2. PMID: 30022717.

Dianat, I., Molenbroek, J., \& Castellucci, H. I. (2018). A Review of The Methodology and Applications of Anthropometry in Ergonomics and Product Design. Ergonomics, 61(12), 1696-1720. doi:10.1080/00140139.2018.1502817.

Ersoy Öztürkler, S. (2009). Yașlı Bireylere Yönelik Referans Değerleri: Erzincan Örneği. Yaşlı Sorunları Araştırma Dergisi, 2, 126-135

Eyvazi, A., \& Mokhtarinia, H. (2017). Pilot Design of Ergonomic Bench for the Elderly With Anthropometric Approach. Physical Treatments, 7(3), 123-132. doi:10.32598/ptj.7.3.123.

Güleç, E., Akın, G., Sağır, M., Koca Özer, B., Gültekin, T., Bektaş, Y. (2009). Anadolu İnsanının Antropometrik Boyutları: 2005 Yılı Türkiye Antropometri Anketi Genel Sonuçları. Ankara Üniversitesi Dil ve Tarih-Coğrafya Fakültesi Dergisi, 49(2), 187-201.

Gültekin, T. Akın, G. (2005). Yaslanmayla Birlikte Boy Uzunluğu ve Oturma (Bust) Yuksekliğinde Meydana Gelen Değisimler. Turkish Journal of Geriatrics, 8(3):125-128. Gündüz, O.H. (2000). "Yașlılarda Postür ve Yürüme". Turkish Journal of Geriatrics. 3: 155- 166.

Jarosz, E. (1999). Anthropometry of Elderly Women in Poland: Dimensions For Design. International
Journal of Industrial Ergonomics, 25(2), 203-213. doi:Doi 10.1016/S0169-8141(99)00011-6.

Kaewdok, T., Sirisawasd, S., Norkaew, S., \& Taptagaporn, S. (2020). Application of Anthropometric Data For Elderly-Friendly Home and Facility Design in Thailand. International Journal of Industrial Ergonomics, 80. doi:10.1016/j.ergon.2020.103037

Kalınkara, V. (2015). Yaşlıların Antropometrik Ölçülerinin İç Mekân Tasarımına Uygulanması. Yaşlı Sorunları Araştırma Dergisi, 8(2), 98-113. Retrieved from https://dergipark.org.tr/en/pub/yasad/issue/2 $1801 / 234296$

Kalınkara, V. (Ed.). (2016). Yaşlılık Disiplinlerarası Yaklaşım, Sorunlar, Çözümler 2. Nobel Akademik Yayıncılık, Ankara.

Kirvesoja, H., Vayryen, S., Haikiö, A. (2000). Three Evaluations of Task-Surface Heights in Elderly People's Home. Applied Ergonomics, 31(2), 10919.

Kothiyal, K., Tetty, S. (2000). Anthropometric Data of Elderly People in Australia. Applied Ergonomic, 31(3), 329-332.

Lohman, T.J., Roache, A., \& Martorell, R. (1988). Anthropometric Standardization Reference Manual.

Molenbroek, J.F.M. (1987). Anthropometry of The Elderly People in The Netherlands; Research and Applications. Applied Ergonomics, 18(3), 187199.

Özalp, B. T. (2020). Determination of Domestic Kitchen Characteristics for Elderly Turkish Women: A Comprehensive Ergonomics Approach. Open Journal of Safety Science and Technology, 10, 53-67. doi:10.4236/ojsst.2020.102005

Özgün Başıbüyük, G., Çınar, Z., Ay, F., \& Bekdaş, 0. (2018). Yaşlı Bireylerin Tuvalet-Banyo Tasarımına Yönelik Antropometrik Ölçüleri ve Pazardaki Ürünlerin Yaşliya Uygunluğunun Değerlendirilmesi. Mühendislik Bilimleri ve Tasarım Dergisi, 6(ÖS: Ergonomi2017), 248-256. doi:10.21923/jesd.358580

Rahmawati, N., Widyanti, A., \& Jiang, B. C. (2020). Daily Life, Anthropometry And Bedroom Design Of Indonesian Elderly. Journal of Accessibility and Design for All, 10(1). doi:10.17411/jacces.v9i2.217

Silva Coqueiro R., Barbosa A. R., Borgatto A. F. (2009). Anthropometric Measurements in The Elderly of Havana, Cuba: Age and Sex Differences, Nutrition, $25: 33-39$. 
Tufan, İ, (2015). Türkiye'de Yaşlılığın Yapısal Değişimi, İstanbul: Koç Üniversitesi Yayınları.

Türkiye İstatistik Kurumu. (2021). İstatistiklerle Yaşlılar, 2020. Retrieved from https://data.tuik.gov.tr/Bulten/Index?p=Istatisti klerle-Yaslilar-2020-37227. Erişim Tarihi: 18.08.2021

Weiner, J. S. \& Lourie, J. A. (1981). Practical human biology. London; New York: Academic Press.

Yardımcı, H. ve Özçelik A Ö. (2006) Ankara İli Gölbaşı İlçesinde Yetişkin Kadınların Antropometrik Ölçümleri ve Beslenme Alışkanlıkları Üzerinde Bir Araştırma" Ankara Üniversitesi Ev Ekonomisi Yüksekokulu Yayın No:13, Bilimsel Araştırma ve İncelemeler:13, Ankara. 